\title{
Properties of $\mathrm{HO}_{2}^{\circ}$ radicals induced by $\gamma$-ray irradiation in silica nanoparticles
}

\author{
G. Buscarino ${ }^{\text {a, } *}$, E.G. Melodia ${ }^{\text {a }}$, A. Alessi ${ }^{\text {a }}$, G. Iovino ${ }^{a}$, A. Parlato ${ }^{\text {b }}$, S. Agnello ${ }^{a}$, M. Cannas ${ }^{\text {a }}$, \\ F.M. Gelardi ${ }^{\mathrm{a}}$, R. Boscaino ${ }^{\mathrm{a}}$ \\ a Dipartimento di Fisica e Chimica, Universita' di Palermo, Via Archirafi 36, I-90123 Palermo, Italy \\ b Dipartimento di Energia Nucleare, Universita' di Palermo, Via delle Scienze, Edificio 6, 90128 Palermo, Italy
}

\section{A R T I C L E I N F O}

\section{Article history:}

Received 10 June 2014

Received in revised form 3 August 2014

Accepted 29 August 2014

Available online $\mathrm{xxxx}$

\section{Keywords:}

$\mathrm{HO}_{2}^{*}$;

$\mathrm{O}_{2}$;

Fumed silica;

Electron paramagnetic resonance

spectroscopy;

Raman spectroscopy

\begin{abstract}
A B S T R A C T
We report an experimental investigation on the effects of $\gamma$-ray irradiation in several types of silica nanoparticles previously loaded with $\mathrm{O}_{2}$ molecules. They differ in specific surface and average diameter. By electron paramagnetic resonance (EPR) measurements we observe the generation of about $10^{18} \mathrm{HO}_{2}^{*} / \mathrm{cm}^{3}$ interstitial radicals. These radicals are induced by reaction of interstitial $\mathrm{O}_{2}$ molecules with radiolytic $\mathrm{H}$ atoms, as previously suggested for $\mathrm{O}_{2}$-loaded bulk a-SiO ${ }_{2}$ samples. However, at variance with respect to bulk materials, our experimental evidences suggest a different generation process of $\mathrm{HO}_{2}^{*}$ radical. In fact, by a detailed study of samples exposed to $\mathrm{D}_{2} \mathrm{O}$, our results prove that radiolytic hydrogen atoms reacting with $\mathrm{O}_{2}$ to produce $\mathrm{HO}_{2}^{-}$mainly arise from a radiation induced breaking of $\mathrm{H}_{2} \mathrm{O}$ molecules in the layers surrounding the nanoparticles or in the interstices. Also, by the correlation of $\mathrm{HO}_{2}$ paramagnetic centers concentration, determined by EPR measurements, and $\mathrm{O}_{2}$ Raman/PL signal we further considered the issue of the direct estimation of the $\mathrm{O}_{2}$ concentration in silica nanoparticles from Raman/PL spectra giving an independent conversion factor (the ratio between these latter two quantities), which is in good agreement with those previously proposed by other authors basing on optical measurements.
\end{abstract}

(c) 2014 Elsevier B.V. All rights reserved.

\section{Introduction}

Here we report on the generation process of point defects in nanostructured silica materials with interstitial $\mathrm{O}_{2}$ molecules. These materials are already frequently used for industrial applications and they are very promising for a large variety of future nanotechnological devices, with vast range of applications in a lot of scientific ambits [1-3]. Moreover, the study of the optical properties of the $\mathrm{O}_{2}$ molecules in all the aggregation states of matter is very interesting due to the abundance of this molecule, for example in the air, and due to its fundamental role in physical, chemical, and biological processes [4-6]. In our systems, they can take part in chemical reactions and generate, among others, hydroperoxy radicals $\left(\mathrm{HO}_{2}^{*}\right)[7-9]$. In this reaction, a- $\mathrm{SiO}_{2}$ plays a key role, thanks to its interstitial voids that absorb the excess energy of the reaction intermediate $[10,11,8]$. Over the years, $\mathrm{HO}_{2}^{-}$radical has been studied in many materials thanks to the possibility to detect the molecule through EPR spectroscopy [12-15]. In particular, in some studies, the radical has been detected in $\mathrm{O}_{2^{-}}$ loaded bulk a- $\mathrm{SiO}_{2}$ irradiated by $\mathrm{F}_{2}$-laser at $\mathrm{T}=77 \mathrm{~K}[7,8]$. It has been shown that, by breaking $\mathrm{O}-\mathrm{H}$ bonds in $\mathrm{SiOH}$ and $\mathrm{SiOOH}$ groups, the radiation induces radiolytic hydrogen atoms that promptly react with interstitial $\mathrm{O}_{2}$ molecules generating the $\mathrm{HO}_{2}^{\circ}$ radicals. By EPR mesurements, Kajihara et al. [7,8] observed, together with the hydroperoxy radicals, a

\footnotetext{
* Corresponding author. Tel.: + 39091238 91725; fax: + 390916162461.

E-mail address: gianpiero.buscarino@unipa.it (G. Buscarino).
}

comparable amount of nonbridging oxygen hole centers (NBOHC) and peroxy radicals (POR) defects.

In the present study we investigate the generation process of $\mathrm{HO}_{2}^{*}$ radicals in silica nanoparticles by $\gamma$-ray irradiation. The nanoparticles differ in specific surface and average diameter. Furthermore, we characterize the EPR signal of hydroperoxy molecules and analize the differences and the analogies between our results and those reported by Kajihara et al. in their study on bulk materials aiming to further clarify the generation of these species in nanoparticles $[7,8]$.

Our experimental investigation also supplies new independent support based on the EPR estimation of defects on the method recently proposed to estimate the amount of interstitial $\mathrm{O}_{2}$ molecules in silica with very high sensitivity by measuring the photoluminescence of $\mathrm{O}_{2}$ molecules by means of a Raman spectrometer. In fact, to detect and evaluate the amount of interstitial $\mathrm{O}_{2}$ one can make use of the electronic transition in $\mathrm{O}_{2}$ from the first excited state ${ }^{1} \Delta_{g}$ to the ground state ${ }^{3} \Sigma_{g}^{-}$. This transition gives rise to an infrared (IR) photoluminescence (PL) band at $\sim 1272 \mathrm{~nm}$ that a Raman spectrometer equipped with a Nd:YAG laser source at $1064 \mathrm{~nm}$ can detect [8,16-20].

\section{Experimental}

The materials considered here are seven types of silica nanoparticles of different average diameters and specific surfaces. Detailed information on the materials and the constituting nanoparticles are reported 
in Table 1. The powders were pressed in a hydraulic press to obtain selfsupporting tablets not altering the structural properties of the fumed silica samples $[21,22]$. All the pristine materials were preventively loaded with $\mathrm{O}_{2}$ molecules by treating them at $\mathrm{T} \sim 200{ }^{\circ} \mathrm{C}$ in oxygen atmosphere $(\mathrm{P}=50 \mathrm{bar})$ for $11 \mathrm{~h}$ [17]. After loading, a natural outgassing process was observed. This process is very fast during the first hours and becomes less efficient with time. In order to limit the deleterious effects of this process on our experiments, after the $\mathrm{O}_{2}$ loading, each sample was aged for 48 hours. This ensures that the $\mathrm{O}_{2}$ concentration present in the samples remains stable within $10 \%$ for the duration of our experiment. Subsequently the materials were subjected to $\gamma$-ray irradiation at various doses in a ${ }^{60} \mathrm{Co}$ source (dose rate of $10.7 \mathrm{~Gy} / \mathrm{min}$ ). Each irradiation was done at ambient temperature and, with few exceptions, in air. In few cases the irradiations were done with the samples immersed in water or heavy water. Irradiation doses ranged from $0.1 \mathrm{kGy}$ to $1000 \mathrm{kGy}$ but every sample was irradiated to just one dose. In our studies we have also considered an $\mathrm{O}_{2}$-loaded bulk a-SiO ${ }_{2}$ sample with size $5 \times 3 \times 2 \mathrm{~mm}^{3}$. It contains network-bound $\mathrm{SiF}\left(1.4 \cdot 10^{19} \mathrm{~cm}^{-3}\right)$ and $\mathrm{SiOH}\left(1 \div 2 \cdot 10^{18} \mathrm{~cm}^{-3}\right)$ groups. For this latter sample the $\mathrm{O}_{2}$ loading was done at $\mathrm{T}=1000{ }^{\circ} \mathrm{C}$ for 30 days. The final $\mathrm{O}_{2}$ concentration was $3.6 \cdot 10^{17} \mathrm{~cm}^{-3}[19,23]$.

FT-Raman measurements were carried out by a Bruker RAMII spectrometer equipped with a Nd:YAG laser source at $1064 \mathrm{~nm}$ $\left(9398 \mathrm{~cm}^{-1}\right.$ ). The optical activity present in Raman spectra (PL band) was used to estimate the $\mathrm{O}_{2}$ content of loaded samples by following the procedure proposed by Kajihara et al. [8]. It uses a conversion factor that has to be multiplied to the amplitude of the $\mathrm{O}_{2} \mathrm{PL}$ band, normalized with respect to the $1200 \mathrm{~cm}^{-1}$ intrinsic Raman band, and gives as a result the desired concentration of $\mathrm{O}_{2}$ molecules. We have to point out that this estimation was limited to a-SiO $\mathrm{S}_{2}$ bulk samples. Here we can extend the use of this procedure to silica nanoparticles considering some multiplying factors to take into account quantum yield variations, as recently reported [24]. They are due to the different life times of the various nanostructured materials studied here with respect to bulk silica [17]. Furthermore, the use of the procedure suggested by Kajihara et al. [8] presents a further difficulty which is accentuated by studying nanostructured samples: the Raman band choosen as reference is one of the less intense and consequently the experimental uncertainty associated to the estimation of its intensity is very large. These facts have leaded us to improve the method by making some changes. We have taken advantage from the work done by Agnello et al. [17,24] where interstitial $\mathrm{O}_{2}$ concentrations were estimated in several a- $\mathrm{SiO}_{2}$ nanostructured samples following the method suggested by Kajihara et al. [8] but considering the differences, reported above or in the following, between nanoparticles and bulk silica. In this context it is worth noting that previous studies have shown that the estimations of $\mathrm{O}_{2}$ absolute concentration by optical measurements are in agreement within $50 \%$ $[8,24]$. We have obtained the conversion factor $K_{i}$, specific for every nanostructured material, by using the following equation:

$C_{O_{2}}=K_{i} \frac{A_{P L}}{A_{800}}$

Table 1

List of the materials utilized. The materials named "SIG-" were supplied by Sigma Aldrich whereas the other materials were obtained from Evonik [27]. ND stays for not declared.

\begin{tabular}{llccl}
\hline Nickname & $\begin{array}{l}\text { Producer } \\
\text { or supplier }\end{array}$ & $\begin{array}{l}\text { Spec. Surf. } \\
\left(\mathrm{m}^{2} / \mathrm{g}\right)\end{array}$ & $\begin{array}{l}\text { Aver. Diam. } \\
(\mathrm{nm})\end{array}$ & Typology \\
\hline AEOX50 & Evonik & 50 & 40 & Fumed \\
AE90 & Evonik & 90 & 20 & Fumed \\
AE200 & Evonik & 200 & 12 & Fumed \\
AE300 & Evonik & 300 & 7 & Fumed \\
AE380 & Evonik & 380 & 7 & Fumed \\
SIG200-12 & Sigma Aldrich & 200 & 12 & ND \\
SIG395 & Sigma Aldrich & 395 & 7 & Fumed \\
\hline
\end{tabular}

where $\mathrm{C}_{\mathrm{O}}$ is the concentration of $\mathrm{O}_{2}$ molecules, whereas $\mathrm{A}_{P L}$ and $\mathrm{A}_{800}$ are the amplitude of the $\mathrm{O}_{2}$ PL band and of the intrinsic Raman band at $800 \mathrm{~cm}^{-1}$, respectively. We can express the factor $K_{i}$ as the ratio between a quantity $\alpha$ (here considered indipendent from the features of the nanoparticles [17-19,22]) and the $\mathrm{O}_{2}$ PL life time $\tau_{i}$ :

$K_{i}=\frac{\alpha}{\tau_{i}}$

Note that in Eq. (1) the amplitude of the intrinsic Raman band at $800 \mathrm{~cm}^{-1}$ is considered instead of that peaked at about $1200 \mathrm{~cm}^{-1}$. We made this choice because the former is more intense than the latter and it has always the same shape, indipendently from the material [25]. Due to this stability, we considered the band at $800 \mathrm{~cm}^{-1}$ suitable to serve as a reference.

From ref. [17] we know the values of $\mathrm{C}_{\mathrm{O} 2}$, of the PL amplitude and of the life time of a sample of AEOX50. Thanks to the Eq. (1) we obtain $\mathrm{K}_{\text {AEOX50 }}=(1.8 \pm 0.4) \cdot 10^{17} \mathrm{~cm}^{-3}$. Now, we have to determine the conversion factors for the other materials considered here. This objective was reached by considering the life times of the materials reported in ref. $[17,24]$. We hypothesized the same life time for all the types of nanoparticles with the same average diameter. In Table 2 we show the life times and the conversion factors for all the materials here analyzed. We considered an absolute error of $\pm 40 \%$ on each value of interstitial $\mathrm{O}_{2}$ concentration. This error includes the repeatability error of the Raman spectrometer, the error introduced in the analysis procedure of the spectra and the error associated with the estimation of the conversion factors.

The $\gamma$-ray induced paramagnetic species were measured at $\mathrm{T}=77 \mathrm{~K}$ with a X-band Bruker EMX-micro-Bay spectrometer (working frequency of about $9.8 \mathrm{GHz}$ ) with a magnetic field modulation frequency of $100 \mathrm{kHz}$. Low temperature spectra were obtained by putting the sample into a Dewar flask filled with liquid nitrogen. Concentrations of paramagnetic centers were determined, with a relative accuracy of $\pm 20 \%$, by comparing the double numerical integral of the EPR spectra with that of the $E_{\gamma}{ }^{\prime}$ centers in a reference sample [26].

\section{Results}

In Fig. 1 the Raman/PL spectra of some pristine sample produced by Evonik are reported: AEOX50, AE200 e AE380. We chose to show these spectra because they cover the whole range of possible average diameter and specific surface. We can see the bands associated with the vibrational modes of silica with a Raman shift lower than about $1200 \mathrm{~cm}^{-1}$ and the $\mathrm{O}_{2}$ PL-band at $1538 \mathrm{~cm}^{-1}$ [8,28-33]. The presence of this latter band tells us that in our samples there is an amount of intrinsic interstitial molecular oxygen decreasing on increasing the specific surface of nanoparticles [22]. The samples SIG200-12 and SIG395 have Raman/PL spectra almost concident to that of Evonik materials, so their spectra are not reported here.

\section{Table 2}

Average diameters and life times taken from ref. [24] and conversion factors used to obtain the interstitial $\mathrm{O}_{2}$ concentration in each material studied here. Life times not experimentally obtained are marked with an asterisk and pertain to the materials SIG200-12 and SIG395. The nanoparticles of these materials, however, have average diameters equal to those of other nanoparticles. Then, for these materials we have considered life times identical to those obtained experimentally.

\begin{tabular}{llll}
\hline Name & Aver. Diam. $(\mathrm{nm})$ & $\tau_{i}(\mathrm{~s})$ & $\mathrm{K}_{i}\left(\mathrm{~cm}^{-3}\right)$ \\
\hline AE0X50 & 40 & $0.46 \pm 0.02$ & $(1.8 \pm 0.4) \cdot 10^{17}$ \\
AE90 & 20 & $0.43 \pm 0.02$ & $(1.9 \pm 0.4) \cdot 10^{17}$ \\
AE200 & 12 & $0.40 \pm 0.03$ & $(2.1 \pm 0.4) \cdot 10^{17}$ \\
SIG200-12 & 12 & $0.40 \pm 0.03 *$ & $(2.1 \pm 0.4) \cdot 10^{17}$ \\
AE300 & 7 & $0.40 \pm 0.03$ & $(2.1 \pm 0.4) \cdot 10^{17}$ \\
AE380 & 7 & $0.34 \pm 0.04$ & $(2.4 \pm 0.5) \cdot 10^{17}$ \\
SIG395 & 7 & $0.34 \pm 0.04^{*}$ & $(2.4 \pm 0.5) \cdot 10^{17}$ \\
\hline
\end{tabular}




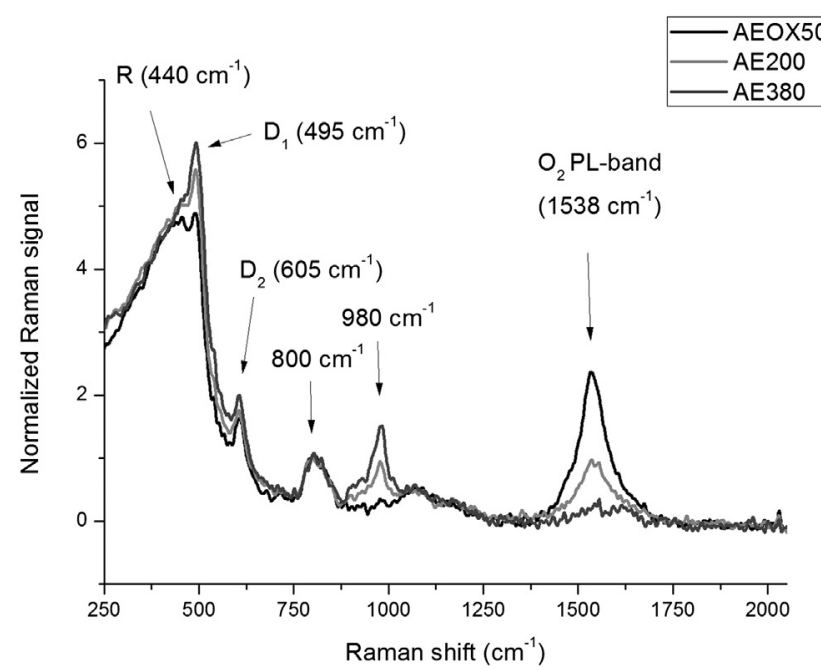

Fig. 1. Raman/PL spectra of three different types of materials: AEOX50 (black line), AE200 (gray line) e AE380 (dark gray line). The arrows show the main bands of the spectra pointing out their names and Raman shifts. Spectra are normalized to the amplitude of the $800 \mathrm{~cm}^{-1}$ band.

In Fig. 2 the Raman/PL spectra of a sample of AEOX50 before and after the $\mathrm{O}_{2}$ loading are shown. The comparison between the two spectra indicates that the loading process significantly increases the concentration of $\mathrm{O}_{2}$ molecules trapped into the material, as indicated by the larger PL band. In the inset we report a zoom of the spectra in the range from 300 to $1200 \mathrm{~cm}^{-1}$. This comparison points out that the differences between the two spectra are negligible, indicating that the loading process does not affect the matrix of the materials.

Beyond the Raman mesurements, we have also performed EPR studies on as grown and $\mathrm{O}_{2}$ loaded materials to detect the presence of $\mathrm{O}_{2}$ related species [9]. Before irradiation, no EPR signal is detected in any of the materials considered here. At variance, after irradiation the characteristic EPR signal of the $\mathrm{HO}_{2}^{-}$radical is clearly observed in all the $\mathrm{O}_{2}$ loaded samples [7-9,13]. Each $\mathrm{HO}_{2}^{\circ}$ molecule involves an unpaired electron primarily located on an oxygen atom of the molecule. Since the materials we have investigated are amorphous, the $\mathrm{HO}_{2}^{-}$radicals induced by irradiation are randomly oriented with respect to the static magnetic field involved in the EPR measurements. This property confers to the EPR line of the $\mathrm{HO}_{2}^{\circ}$ the characteristic powder lineshape. Furthermore,

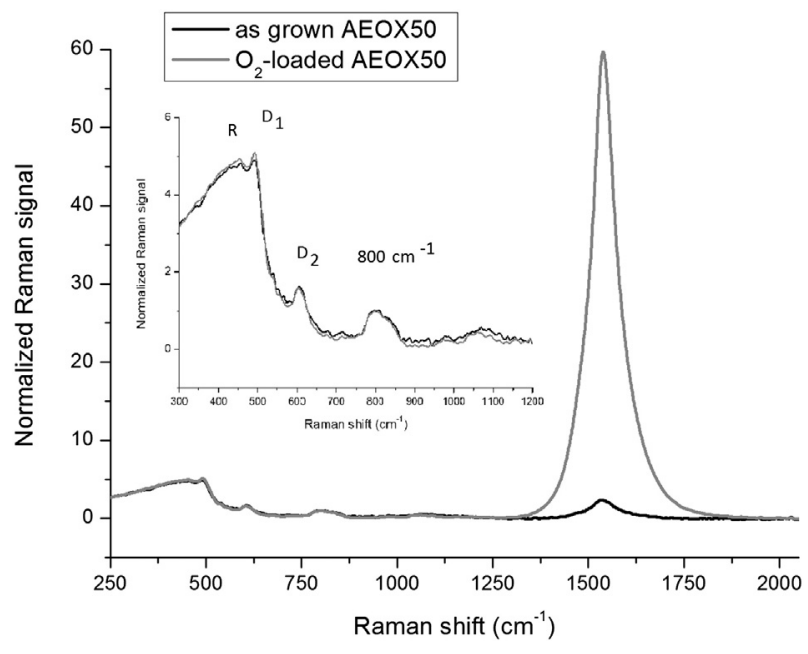

Fig. 2. Normalized Raman/PL spectra of AEOX50 pristine (black line) and $\mathrm{O}_{2}$ loaded (grey line). The main difference we can see is in the PL intensity at $1538 \mathrm{~cm}^{-1}$ and it is due to the difference between the $\mathrm{O}_{2}$ concentration in the two samples. In the insert the magnification of the spectral region between 300 and $1200 \mathrm{~cm}^{-1}$ is shown. In the insert, the main bands of the spectra are indicated. since the unpaired electron of the $\mathrm{HO}_{2}^{\circ}$ radical is weakly coupled via the hyperfine interaction with the magnetic nucleus of the $\mathrm{H}$ atom involved in the molecule, its EPR spectrum actually comprises a couple of powder lines, instead of a single one, with a separation of about 1.3 $\mathrm{mT}$.

In Fig. 3 we compare the EPR spectra of two samples at $\mathrm{T}=77 \mathrm{~K}$ irradiated at the dose of $150 \mathrm{kGy}$ : AEOX50 (black line) and AE380 (gray line). The chosen samples are representative ones because AEOX50 and AE380 have specific surfaces and average diameters on the opposite extremes. We can see that the line shape of the EPR resonance is found to be virtually indistinguishable for the AEOX50 and AE380 materials. This is true also for all the other analized materials. This result shows how the differences in the structural properties of the various materials don't influence the line shape of the EPR resonance in the spectral region here analized.

In Fig. 4 we show the normalized Raman/PL spectra obtained for the $\mathrm{O}_{2}$ loaded a- $\mathrm{SiO}_{2}$ bulk sample before (gray line) and after (black line) irradiation at the dose of $\sim 10 \mathrm{kGy}$. The irradiation doesn't modify a- $\mathrm{SiO}_{2}$ structural Raman bands and the little difference in the PL intensity of the $\mathrm{O}_{2}$ band is commented in the following.

We have also studied by EPR technique the paramagnetic centers induced by irradiation in the bulk sample. In Fig. 5 the comparison between the EPR line shapes obtained at $\mathrm{T}=77 \mathrm{~K}$ from the $\mathrm{a}-\mathrm{SiO}_{2}$ bulk sample and from an AEOX50 sample irradiated the same dose of $10 \mathrm{kGy}$ is shown. The spectra are similar in shape but in the black spectrum you may notice a bifurcation of the peak at $340 \mathrm{mT}$ and a new peak at $341 \mathrm{mT}$. The bulk sample spectrum (black line) is very similar to that obtained for the same material after laser $F_{2}$ irradiation and reported elsewhere [7,8]. After $\gamma$-ray irradiation and laser $F_{2}$ irradiation one can obtain the same paramagnetic centers: $\mathrm{HO}_{2}^{\circ}, \mathrm{NBOHC}, \mathrm{POR}$ and $\mathrm{E}_{\gamma}{ }^{\prime}$. NBOHC (Non Bridging Oxygen Hole Center) and POR (Peroxy Radical) defects both involve an unpaired electron located on the $\mathrm{O}$ atom of the $\mathrm{Si}-\mathrm{O}^{\circ}$ and $\mathrm{Si}-\mathrm{O}-\mathrm{O}^{\circ}$ groups, respectively, whereas the $\mathrm{E}_{\gamma}{ }^{\prime}$ center involves an unpaired electron located on a $\mathrm{sp}^{3}$ dangling bond of an $\mathrm{Si}$ atom bonded to three $\mathrm{O}$ atoms of the matrix of the material. From the EPR spectrum in Fig. 5 we have estimated a concentration of $\mathrm{HO}_{2}^{\circ}$ of $\sim 10^{16} \mathrm{spin} / \mathrm{cm}^{3}$ for the bulk silica sample, which corresponds to about $3 \%$ of initial $\mathrm{O}_{2}$ content and is in reasonable agreement with PL changes detected by Raman spectra.

We studied also the variation of concetration of $\mathrm{HO}_{2}^{\circ}$ and $\mathrm{O}_{2}$ molecules with the dose of irradiation. To do this, we had to take into account the natural outgassing of the interstitial $\mathrm{O}_{2}$ molecules in our sample [34]. With the aim to overcome this problem, we have loaded simultaneously with $\mathrm{O}_{2}$ many samples of AEOX50 (the reader will verify in the following that the material is the one with the higher oxygen

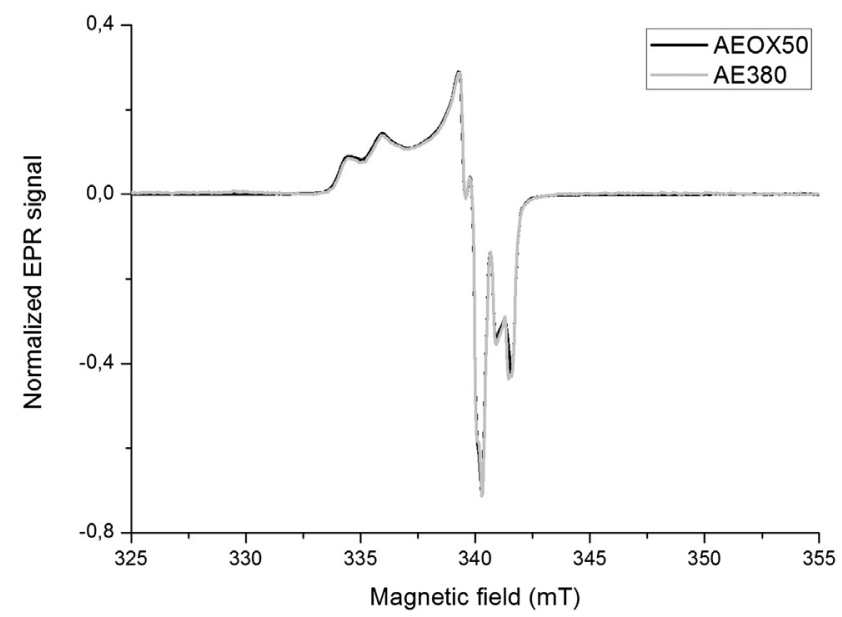

Fig. 3. EPR spectra of $\mathrm{HO}_{2}^{*}$ in the samples AEOX50 (black line) and AE380 (gray line). Spectra are obtained at $\mathrm{T}=77 \mathrm{~K}$ on irradiated samples at the dose of $150 \mathrm{kGy}$. Spectra are normalized to the peak-to-peak amplitude. 


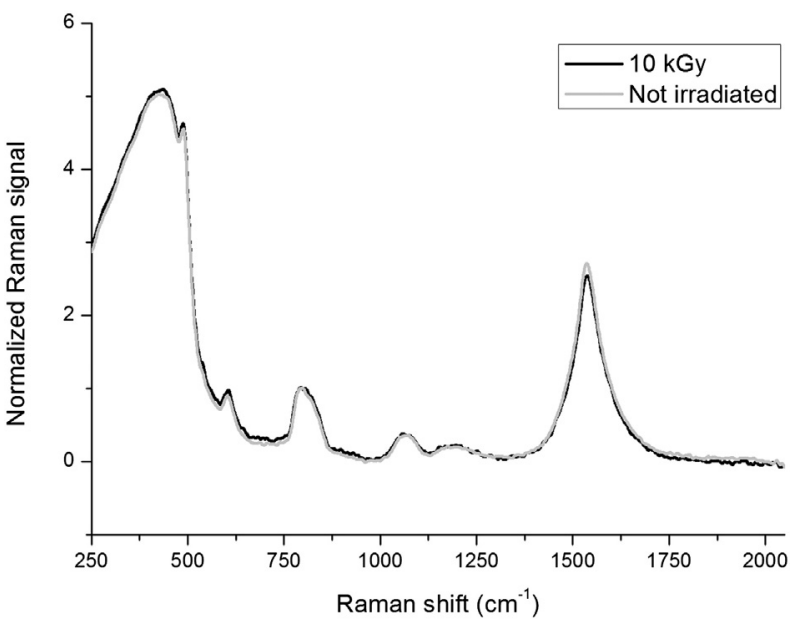

Fig. 4. Normalized Raman/PL spectra obtained from the bulk sample before (gray line) and after (black line) the irradiation at the dose of $10 \mathrm{kGy}$. Spectra are normalized to the amplitude of the $800 \mathrm{~cm}^{-1}$ band.

content) and we have chosen the duration of irradiations so that the variation of $\mathrm{O}_{2}$ in time caused by outgassing was negligible. We have irradiated each sample at a different dose from $0.1 \mathrm{kGy}$ to $1000 \mathrm{kGy}$. We have found that, at every irradiation dose, the main feature of Raman/ PL and EPR spectra are the same as those showed before. In Fig. 6 we report the interstitial $\mathrm{HO}_{2}^{\circ}$ concentration in AEOX50 as a function of the dose of irradiation for each sample. Each point in the graphic was obtained from a different sample. Interstitial $\mathrm{HO}_{2}^{*}$ concentration linearly increases with the dose up to $10 \mathrm{kGy}$. For higher doses the generation process of $\mathrm{HO}_{2}^{-}$starts to be less efficient. For a dose of $1000 \mathrm{kGy}$ the interstitial $\mathrm{HO}_{2}^{\circ}$ concentration undergoes a drastic decrease. After this last irradiation the interstitial $\mathrm{O}_{2}$ concentration is about $3 \%$ of the concentration detected before. Probably, the reaction which governs the generation of the $\mathrm{HO}_{2}^{-}$molecules is gradually less efficient increasing the irradiation dose due to the lacking of $\mathrm{O}_{2}$ molecules that can react.

We estimate also the interstitial $\mathrm{O}_{2}$ concentration in the irradiated samples. In Fig. 7 we report the variation of $\mathrm{O}_{2}$ concentration on increasing the irradiation dose. We can see that the trend of the curve is very similar to that of Fig. 6: for doses lower than about $10 \mathrm{kGy}$ the trend is linear, whereas for higher doses there is a saturation trend.

With the aim to deepen the understanding of the production mechanism that leads to the generation of the $\mathrm{HO}_{2}^{-}$radical we have irradiated some samples of AEOX50 immersed in $\mathrm{H}_{2} \mathrm{O}$ or $\mathrm{D}_{2} \mathrm{O}$. To further detail the

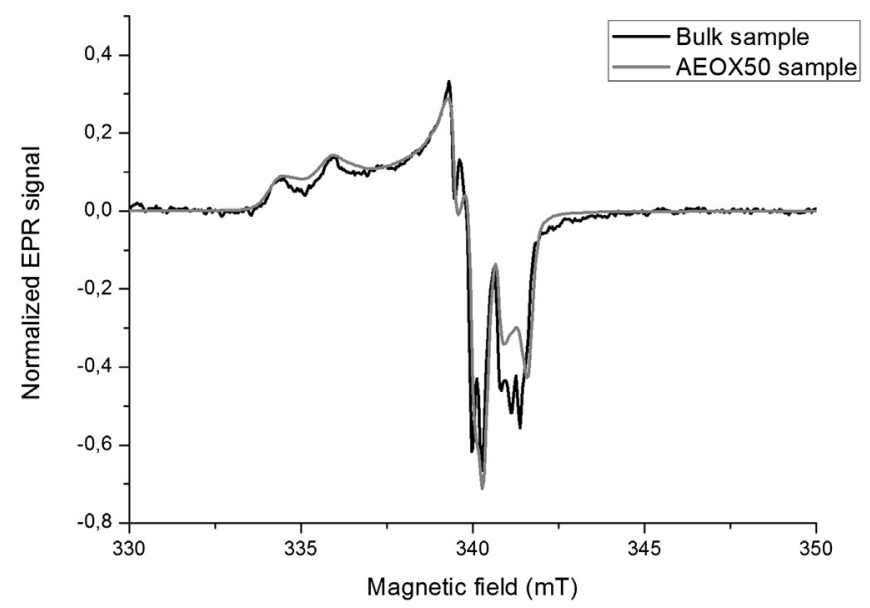

Fig. 5. Normalized EPR spectra obtained at $\mathrm{T}=77 \mathrm{~K}$ in the a-SiO $\mathrm{O}_{2}$ bulk sample after the irradiation with a dose of $10 \mathrm{kGy}$ (black line) and in an $\mathrm{O}_{2}$ loaded AEOX50 sample after the irradiation at the same dose (gray line). Spectra are normalized to the peak-to-peak amplitude.

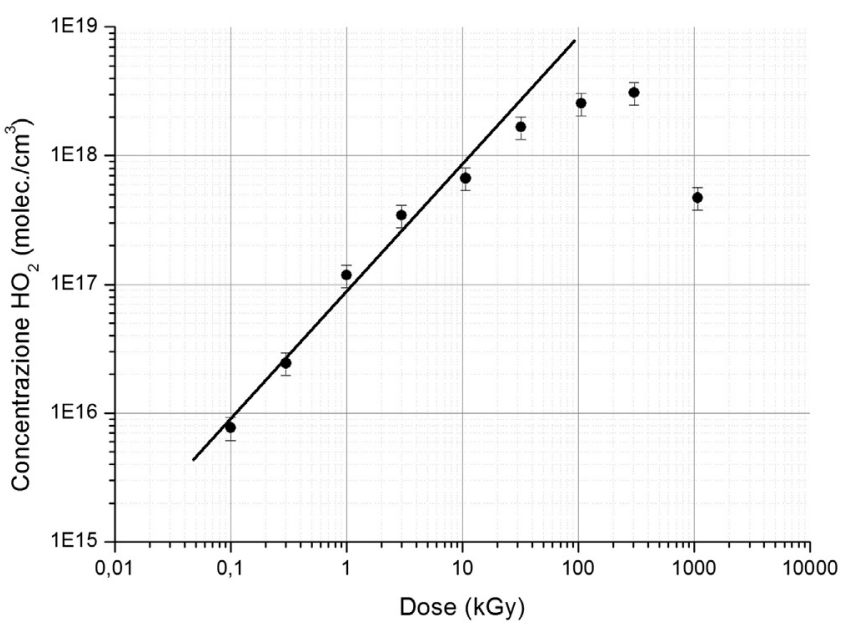

Fig. 6. Interstitial $\mathrm{HO}_{2}^{-}$concentration in $\mathrm{AEOX} 50$ as a function of the dose of irradiation.

experiment: three samples of AEOX50 were $\mathrm{O}_{2}$ loaded simultaneously; one of them was irradiated in air, whereas the other two samples were irradiated while they were immersed in water (AEOX50 in $\mathrm{H}_{2} \mathrm{O}$ ) and in heavy water (AEOX50 in $\mathrm{D}_{2} \mathrm{O}$ ). The irradiation dose was of about $60 \mathrm{kGy}$. At the end of the irradiation we let the samples dry themselves off in the air for some hours. Before and after the irradiation we have done Raman and EPR measurements. In Fig. 8 we show the Raman/PL spectra obtained after the irradiation. They are almost identical for Raman shift less than $\sim 1300 \mathrm{~cm}^{-1}$. For larger Raman shift we can see a difference in the intensities of the PL bands and, only in the spectrum of the sample immersed in $\mathrm{D}_{2} \mathrm{O}$, a large band at $\sim 2500 \mathrm{~cm}^{-1}$. This band is due to the vibration of the $\mathrm{D}_{2} \mathrm{O}$ molecules that cover the nanoparticles [35].

In Fig. 9 we show the EPR spectra at $\mathrm{T}=77 \mathrm{~K}$ of the samples of AEOX50 irradiated in $\mathrm{H}_{2} \mathrm{O}$ and in air. We can see that the immersion of the sample in water doesn't modify the EPR line shape of the signal obtained.

In Fig. 10 we show the EPR spectrum at $\mathrm{T}=77 \mathrm{~K}$ obtained from the sample of AEOX50 irradiated immersed in $\mathrm{D}_{2} \mathrm{O}$. At once, we can notice that the EPR line shape is very different with respect to that showed in Fig. 9. Furthermore, we note that Kajihara et al. obtained the same line shape by irradiating with $\mathrm{F}_{2}$ laser an a- $\mathrm{SiO}_{2}$ bulk sample in which the $\mathrm{SiOH}$ groups were substituted with $\mathrm{SiOD}$ groups [7]. Since this signal was attributed to the $\mathrm{DO}_{2}^{\circ}$ radical, we can reasonably conclude that $\gamma$ irradiating a sample of AEOX50 immersed in $\mathrm{D}_{2} \mathrm{O}$ we obtain the $\mathrm{DO}_{2}^{*}$ radical instead of the $\mathrm{HO}_{2}^{\circ}$ radical [7].

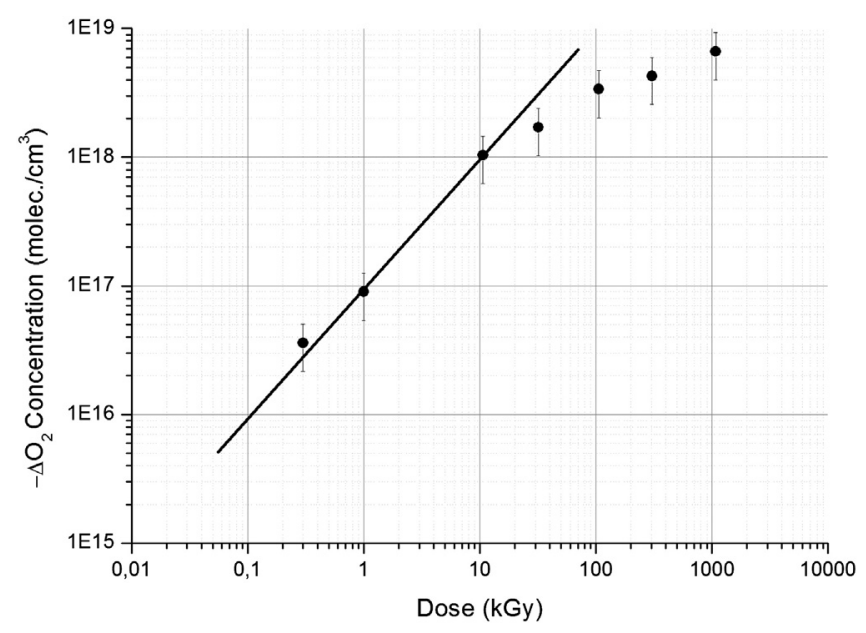

Fig. 7. Variation of interstitial $\mathrm{O}_{2}$ concentration in AEOX50 as a function of the irradiation dose. 


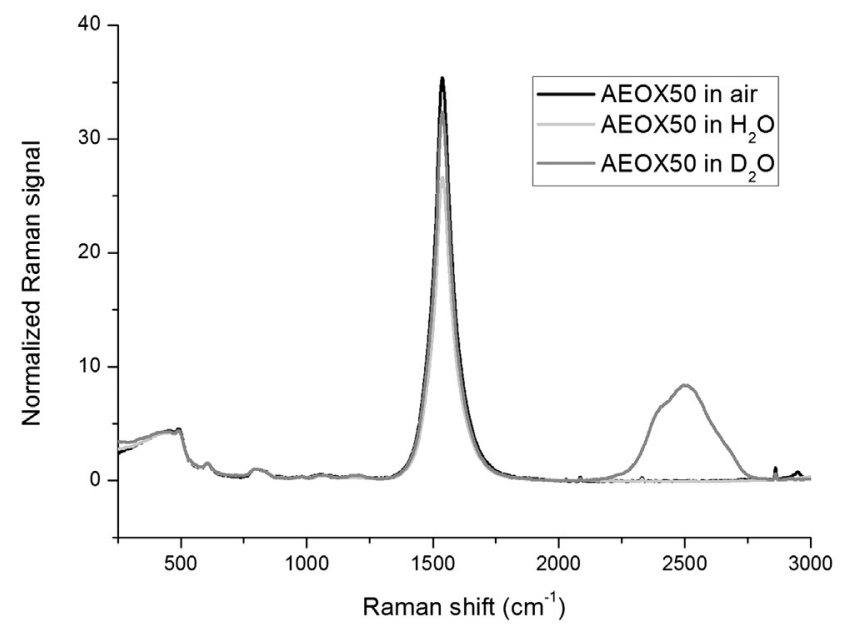

Fig. 8. Raman/PL spectra obtained on the samples of AEOX50 after the irradiation at $60 \mathrm{kGy}$ in air (black line), in water (gray line) and in heavy water (dark gray line). Spectra are normalized to the amplitude of the $800 \mathrm{~cm}^{-1}$ band.

\section{Discussion}

In Table 3 we show specific surface, average diameter and interstitial $\mathrm{O}_{2}$ concentration before and after the loading process for the materials studied here. We can analyze the efficiency of the loading process and the relationship between obtained values and the features of the materials. It can be noted that interstitial $\mathrm{O}_{2}$ concentration increases by a factor almost 20 compared to the pristine values. This demonstrates the effectiveness of the loading process [17]. Furthermore, we can see that the interstitial $\mathrm{O}_{2}$ concentration decreases with increasing specific surface area [22].

We then consider the concentration of interstitial $\mathrm{HO}_{2}^{\circ}$ molecules in the studied materials for two doses of irradiation (50 kGy and $150 \mathrm{kGy}$ ) with the aim to analyze the relationship between $\mathrm{HO}_{2}^{\circ}$ concentration and the features of nanoparticles. In Table 4 we show specific surface, average diameters and $\mathrm{HO}_{2}^{*}$ concentration for both the irradiations. Also in this case, the larger the diameter (and the smaller the specific surface), the more $\mathrm{HO}_{2}^{\circ}$ are observed in the samples.

One of our goals of the present work is to compare the effect of an irradiation process on bulk and nanostructured silica samples and to clarify the irradiation conversion of $\mathrm{O}_{2}$ species. Our reference for the study of bulk samples is the work of Kajihara et al. [7,8] who studied the $\mathrm{HO}_{2}^{-}$radical in $\mathrm{O}_{2}$-loaded bulk a-SiO${ }_{2}$ irradiated by $\mathrm{F} 2$-laser at $\mathrm{T}=$ $77 \mathrm{~K}$. In their samples, through EPR mesurements, Kajihara et al.

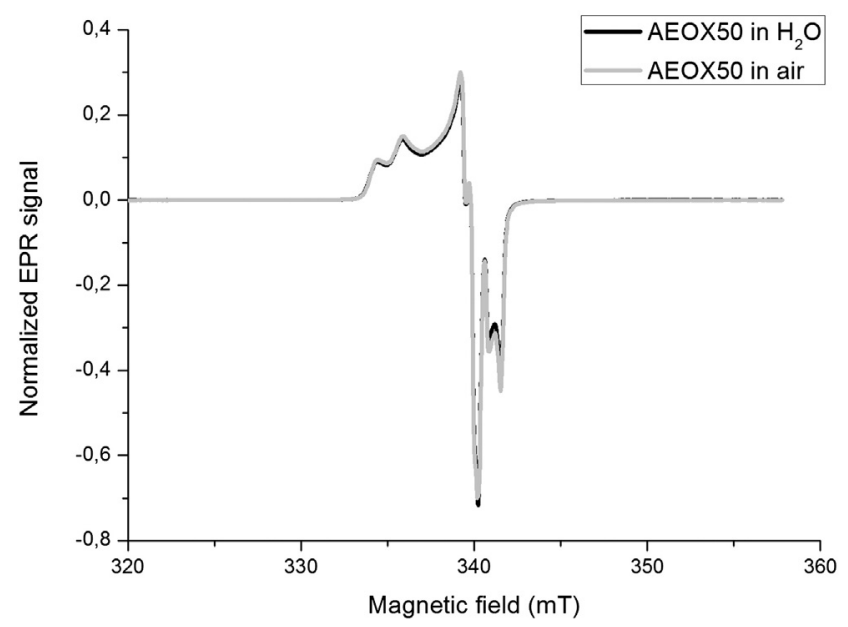

Fig. 9. EPR spectra obtained at $\mathrm{T}=77 \mathrm{~K}$ for two samples of AEOX50 irradiated in water (black line) and in air (gray line). Spectra are normalized to the peak-to-peak amplitude.

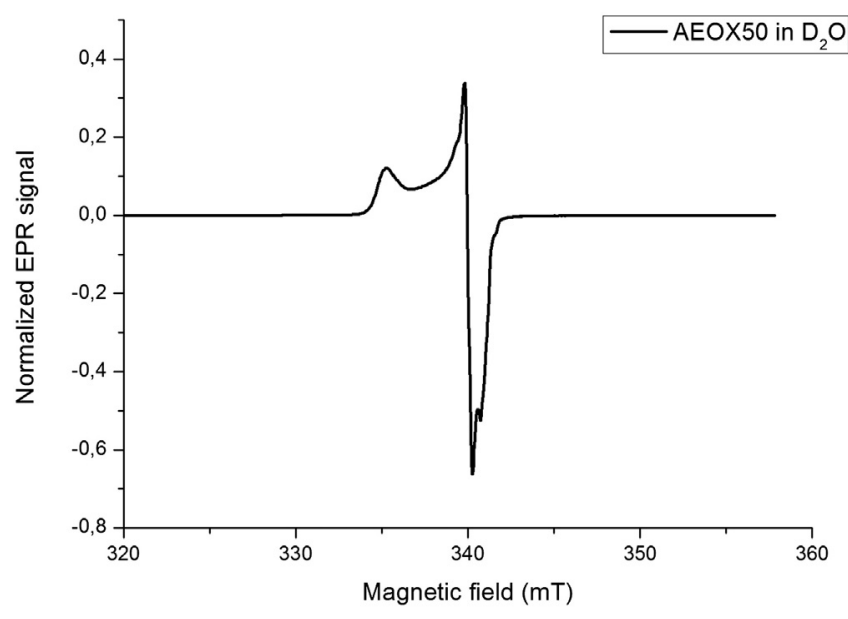

Fig. 10. EPR spectrum at $T=77 \mathrm{~K}$ obtained from the sample of AEOX50 irradiated immersed in $\mathrm{D}_{2} \mathrm{O}$. Spectra are normalized to the peak-to-peak amplitude.

observed, together with the hydroperoxy radicals, a comparable amount of NBOHC plus POR. As said, we have analyzed $\mathrm{O}_{2}$-loaded nanostructurated $\gamma$-ray irradiated a- $\mathrm{SiO}_{2}$ samples. Comparing our results with those of Kajihara et al. [7,8] we can note a significant difference in the paramagnetic centers produced. In principle, these differences can be due to the different irradiation methods considered. To clarify this point we $\gamma$ irradiated an $\mathrm{O}_{2}$-loaded bulk sample. Our results (Fig. 5) are consistent with those obtained from Kajihara et al. in ref. [7]. From this analysis it is possible to conclude that the nature of the irradiation considered does not influence the type of paramagnetic centers induced in the bulk material. By extension, we can assume that the different results obtained by irradiating silica nanostructured or bulk materials are exclusively due to the type of materials and to their properties and not to the type of radiation experienced. This result strongly strengthens the supposition that the mechanism of generation of the $\mathrm{HO}_{2}^{-}$centers in a-SiO${ }_{2}$ nanoparticles is significantly different with respect to that acting in bulk a-SiO ${ }_{2}$.

The analysis of the Figs. 6 and 7 let us to make some observations on the generation process of the $\mathrm{HO}_{2}^{\circ}$ radical in nanostructured samples. We can see that the increase in $\mathrm{HO}_{2}^{\circ}$ concentration is accompanied by a similar decrease in $\mathrm{O}_{2}$ concentration. This lets us to infer that the source of oxygen in the process of formation of the $\mathrm{HO}_{2}^{\circ}$ radical is the interstitial oxygen and not the structural oxygen. This also happens in the a-SiO 2 bulk samples studied by Kajihara et al. in ref. [7].

From the analysis of Figs. 6 and 7 we can suggest a strong quantitative correlation between the amount of $\mathrm{HO}_{2}^{\circ}$ produced by irradiation and the variation of $\mathrm{O}_{2}$ content. This is true for all the materials studied in this work. To further support this point we show in Fig. 11 the correlation between the $\mathrm{HO}_{2}^{-}$concentration produced and the revised $\mathrm{PL}$ intensity, $\mathrm{I}_{\text {PLrevised, }}$, defined in the following. We know that the PL intensity is proportional to the interstitial $\mathrm{O}_{2}$ concentration. Considering that in our measurements we have referred the oxygen PL amplitude $A_{P L}$ to

Table 3

Interstitial $\mathrm{O}_{2}$ concentrations in all the $\mathrm{a}-\mathrm{SiO}_{2}$ nanostructured materials before and after the loading process.

\begin{tabular}{lllll}
\hline Name & $\begin{array}{l}\text { Specif. Surf. } \\
\left(\mathrm{m}^{2} / \mathrm{g}\right)\end{array}$ & $\begin{array}{l}\text { Aver. Diam. } \\
(\mathrm{nm})\end{array}$ & $\begin{array}{l}\mathrm{O}_{2} \text { Conc. pre load. } \\
\left(10^{18} \mathrm{molec} . / \mathrm{cm}^{3}\right)\end{array}$ & $\begin{array}{l}\mathrm{O}_{2} \text { Conc. post load. } \\
\left(10^{18} \mathrm{molec} . / \mathrm{cm}^{3}\right)\end{array}$ \\
\hline AEOX50 & 50 & 40 & $0.42 \pm 0.17$ & $9 \pm 4$ \\
AE90 & 90 & 20 & $\approx 0.4$ & $7 \pm 3$ \\
AE200 & 200 & 12 & $0.19 \pm 0.08$ & $4.3 \pm 1.7$ \\
SIG200-12 & 200 & 12 & $0.21 \pm 0.08$ & $4.1 \pm 1.6$ \\
AE300 & 300 & 7 & $0.08 \pm 0.03$ & $1.8 \pm 0.7$ \\
AE380 & 380 & 7 & $0.06 \pm 0.02$ & $1.2 \pm 0.5$ \\
SIG395 & 395 & 7 & $0.05 \pm 0.02$ & $1.0 \pm 0.4$ \\
\hline
\end{tabular}


Table 4

Interstitial $\mathrm{HO}_{2}^{-}$concentrations in the silica nanoparticles here studied after irradiations at doses of $50 \mathrm{kGy}$ and $150 \mathrm{kGy}$.

\begin{tabular}{lccll}
\hline Name & Specif. Surf. $\left(\mathrm{m}^{2} / \mathrm{g}\right)$ & Aver. Diam. $(\mathrm{nm})$ & \multicolumn{2}{l}{$\begin{array}{l}\mathrm{HO}_{2}^{*} \text { Conc. } \\
\left(10^{17} \mathrm{molec} .\right.\end{array}$} \\
\cline { 3 - 5 } & & & $\left.50 \mathrm{~cm})^{3}\right)$ \\
\hline AEOX50 & 50 & 40 & $21 \pm 4$ & $150 \mathrm{kGy}$ \\
AE90 & 90 & 20 & $13 \pm 3$ & $20 \pm 6$ \\
AE200 & 200 & 12 & $7.2 \pm 1.4$ & $8.0 \pm 1.6$ \\
SIG200-12 & 200 & 12 & $7.0 \pm 1.4$ & $\approx 8$ \\
AE300 & 300 & 7 & $1.9 \pm 0.4$ & $2.9 \pm 0.6$ \\
AE380 & 380 & 7 & $1.0 \pm 0.2$ & $1.5 \pm 0.3$ \\
SIG395 & 395 & 7 & $1.0 \pm 0.2$ & $1.7 \pm 0.3$ \\
\hline
\end{tabular}

the Raman band at $800 \mathrm{~cm}^{-1}$ we can define the PL intensity $\mathrm{I}_{P L}$ as:

$I_{P L}=\frac{A_{P L}}{A_{800}}$

The proportionality factor between the $\mathrm{O}_{2}$ concentration and the PL intensity $\mathrm{I}_{P L}$ just defined is equal to the ratio between $\alpha$, a quantity assumed independent of the type of nanoparticle considered $[18,19]$, and the PL lifetimes. Taking advantage of this consideration it is possible to define $\mathrm{I}_{\text {PLrevised: }}$

$I_{\text {PLrevised } i}=I_{P L i} \cdot \frac{\tau_{A E O X 50}}{\tau_{i}}$

Differently from $\mathrm{I}_{P L i}, \mathrm{I}_{P L \text { Lrevised } i}$ is independent from the features of the material thanks to the normalization with $\tau_{i}$. Moreover, taking advantage from Eq. (2) we can obtain:

$I_{\text {PLrevised } i}=\frac{C_{\mathrm{O}_{2} i}}{K_{\mathrm{AEOX} 50}}$

The quantity $I_{\text {PLrevised } i}$ is important because it is proportional to the $\mathrm{O}_{2}$ concentration and the constant of proportionality is the inverse of the factor $\mathrm{K}_{\text {AEOX50 }} \sim 1.8 \cdot 10^{17} \mathrm{~cm}^{-3}$ as determined basing on reference [17].

On the basis of the data reported in Figs. 6 and 7 we can suppose that in each experiment the observed decrease in the interstitial $\mathrm{O}_{2}$ concentration is due essentially to the reaction that gives rise to formation of the $\mathrm{HO}_{2}^{-}$radicals. So, in Fig. 11 we report the variation of $\mathrm{I}_{\text {PLrevised }}$ as a

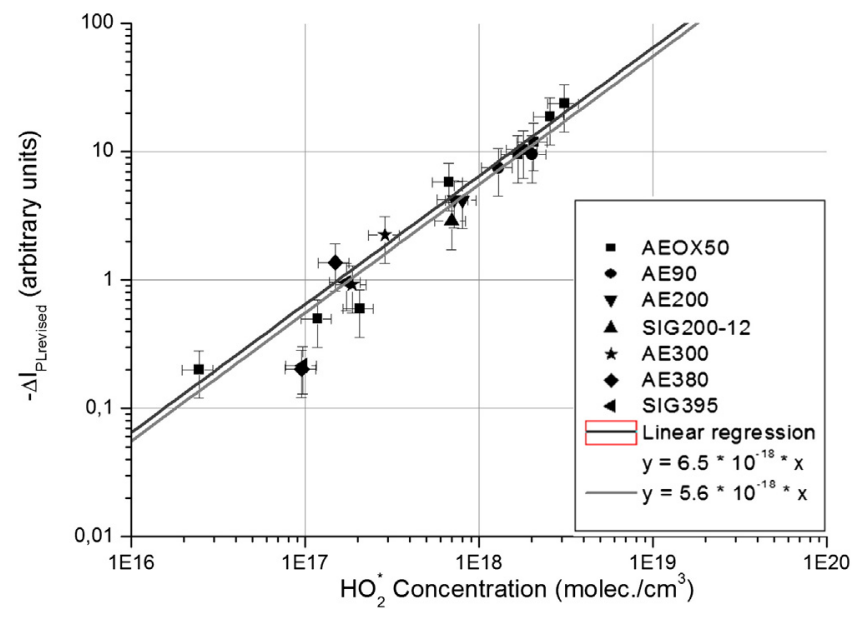

Fig. 11. Correlation graph between the variation of $\mathrm{I}_{\text {PLrevised }}$ and the $\mathrm{HO}_{2}$ concentration in all the materials here studied. Both axes of the graph are shown in logarithmic scale to allow easier recognition of the linear dependence. The gray line represents the linear regression with fixed intercept through the origin. The dark gray line represents the expected trend with slope of $5.6 \cdot 10^{-18}$. This value is the inverse of $\mathrm{K}_{A E O X 50}$, obtained from the work of Kajihara et al. in ref. [8] (see text). function of the $\mathrm{HO}_{2}^{\circ}$ concentration. Both axes of the graph are in logarithmic scale to allow easier recognition of the linear dependence presented. On the basis of the discussion reported above, we expect that the data follow the straight line with slope $1 / \mathrm{K}_{\text {AEOX50 }}=$ $5.6 \cdot 10^{-18} \mathrm{~cm}^{3}$. In Fig. 11 the dark gray line represents the expected trend while the gray line represents the linear regression of the experimental data by fixing the intercept on the origin of axes. The linear trend allows us to support with good confidence that, in every case, during the irradiation process the only significant process that causes the decrease of the $\mathrm{O}_{2}$ concentration is the generation process of the $\mathrm{HO}_{2}^{\circ}$ radical. The slope of the linear regression line is $\sim 6.5 \cdot 10^{-18} \mathrm{~cm}^{3}$ and its inverse is equal to $1.5 \cdot 10^{17} \mathrm{~cm}^{-3}$. This estimate provides a new conversion factor that allows to obtain the interstitial $\mathrm{O}_{2}$ concentration from the PL intensity in the Raman spectra. This latter value is independent from those obtained from data previously reported in the literature $[8,24,36]$ because the methodology used is different. The previous values were obtained in three separate experimental works $[8,24]$, so it is of considerable importance that the conversion factor obtained by us (about $1.5 \cdot 10^{17} \mathrm{~cm}^{-3}$ ) is compatible with the values that can be obtained basing on previous investigation $\left(\mathrm{K}_{A E O X 50} \sim 1.8 \cdot 10^{17} \mathrm{~cm}^{-3}\right.$ obtained from the work done by Kajihara et al. [8]; $\mathrm{K}_{A E O X 50} \sim 3.5 \cdot 10^{17} \mathrm{~cm}^{-3}$ from the work done by Skuja et al. [36]; $\mathrm{K}_{A E O X 50} \sim 0.9 \cdot 10^{17} \mathrm{~cm}^{-3}$ from the work done by Agnello et al. [24]) using the amplitude ratio of the $\mathrm{SiO}_{2}$ Raman bands at $1000-1200 \mathrm{~cm}^{-1}$ and the $\mathrm{O}_{2}$ Raman/PL spectra. In this context it is worth to remember that the error reported for the optical estimation of the conversion factoris about $50 \%$.

Now we can discuss about the generation process of the $\mathrm{HO}_{2}^{\circ}$ radical in $\mathrm{O}_{2}$-loaded fumed silica. Our EPR spectra reported in Fig. 3 essentially represent the proper $\mathrm{HO}_{2}^{\circ}$ line shape. At variance, with respect to previous experimental investigations focused on bulk a- $\mathrm{SiO}_{2}$ [7,8,37], in our spectra no signals ascribable to NBOHC and POR radicals have been clearly detected. This suggests that these latter defects, if present, are induced in a significantly lower concentration in fumed silica upon irradiation with respect to the other paramagnetic defects. To further support this point, in ref. [9] some irradiated samples were subjected to $\mathrm{H}_{2}$ loading because NBOHC radicals are known to be very reactive with these molecules [7]. Consequently, the treatment of $\mathrm{H}_{2}$ loading is expected to cancel out the contribution of these centers to the overall EPR spectrum. Buscarino et al. [9] showed that the treatment does not affect the resonance line shape at all, strongly supporting the conclusion that in comparison with the $\mathrm{HO}_{2}^{\circ}$ no significant concentration of NBOHC and POR are induced in $\mathrm{O}_{2}$-loaded fumed silica upon $\gamma$-ray irradiation. This finding indicates that the source of the hydrogen which interacts with $\mathrm{O}_{2}$ molecules to give $\mathrm{HO}_{2}^{-}$radicals, doesn't arise from $\mathrm{SiOH}$ or $\mathrm{SiOOH}$ groups, as in the case of bulk a-SiO${ }_{2}$. Furthermore, the hydrogen source can not even consist in $\mathrm{H}_{2}$ molecules dissolved into the as-grown material, as they are expected to escape efficiently from the material by rapid diffusion at room temperature. A plausible alternative hypothesis, proposed in ref. [9], states that the hydrogen atoms that react with $\mathrm{O}_{2}$ to form $\mathrm{HO}_{2}^{*}$ may come from the radiation induced breaking of the $\mathrm{H}_{2} \mathrm{O}$ molecules inside the material and those covering the nanoparticles [38-40]. In order to test this hypothesis an experiment has been developed that has allowed us to clarify the issue. The experiment consisted in some irradiations with the samples immersed in water or heavy water, whose results are reported in Figs. 8, 9 and 10. In Fig. 9 the EPR spectra of the samples of AEOX50 irradiated in $\mathrm{H}_{2} \mathrm{O}$ and that of the sample irradiated in air show that the immersion of the sample in water doesn't modify the EPR line shape of the signal obtained. At variance, the spectrum reported in Fig. 10 allows us to conclude that $\gamma$ irradiating a sample of AEOX50 immersed in $\mathrm{D}_{2} \mathrm{O}$ we obtain the $\mathrm{DO}_{2}^{*}$ radical instead of the $\mathrm{HO}_{2}^{-}$radical. This effect can be explained considering that immersing the sample studied in $\mathrm{D}_{2} \mathrm{O}$, it quickly replaces the water molecules surrounding the nanoparticles. In addition, from literature data, it is known that water molecules diffuse in a-SiO ${ }_{2}[41]$ and then it is reasonable to expect the same also for molecules of heavy water. This allows us to say with good confidence that, in addition to 
the layer surrounding the nanoparticles, $\mathrm{H}_{2} \mathrm{O}$ and, in the experiment with heavy water, $\mathrm{D}_{2} \mathrm{O}$ molecules are present in the interstices of the material. The result of the experiment of irradiation in $\mathrm{D}_{2} \mathrm{O}$ confirms that the water molecules are the source of hydrogen in the formation of interstitial $\mathrm{HO}_{2}^{-}$in silica nanoparticles. This finding highlights that the different generation process of $\mathrm{HO}_{2}^{\circ}$ observed in silica nanoparticles with respect to bulk silica is mainly due to the different structural properties of the two materials. The predominant role is played by the specific surface, much larger in the nanoparticles than the bulk. This aspect makes the availability of water significantly higher in the first system than in the latter and it is very important because, due to the small size of the nanoparticles, the hydrogen atoms produced by irradiation can easily and quickly reach the whole volume of the material.

Finally, it is necessary to pay attention to the $\mathrm{HO}_{2}^{-}$and $\mathrm{DO}_{2}^{\circ}$ concentrations generated during irradiation (Table 5). We can immediately notice the significant difference between these quantities related to the two immersed samples compared to those we have observed in the sample irradiated in air. For the two immersed samples, we can see larger $\mathrm{HO}_{2}^{-}$and $\mathrm{DO}_{2}^{*}$ concentrations and a higher $\mathrm{O}_{2}$ concentration variation compared to what we can see for the sample irradiated in air. This behaviour can be explained with the considerably greater amount of $\mathrm{H}_{2} \mathrm{O}$ and $\mathrm{D}_{2} \mathrm{O}$ surrounding the nanoparticles in the two cases. Nevertheless, even in the samples irradiated in immersion the correlation between the $\mathrm{HO}_{2}^{\circ}$ and $\mathrm{DO}_{2}^{\circ}$ concentration generated by radiation and the $\mathrm{O}_{2}$ concentration variation is satisfied.

\section{Conclusion}

We have reported an investigation on the generation process of $\mathrm{HO}_{2}^{*}$ radicals by $\gamma$-ray irradiation in $\mathrm{O}_{2}$-loaded silica nanoparticles of different types. By the combined Raman and EPR investigation of irradiated samples we confirmed that the generation process of the $\mathrm{HO}_{2}^{\circ}$ molecule in nanoparticles is different with respect to that in bulk silica. In fact, in the former system $\mathrm{HO}_{2}^{*}$ radicals are generated upon room temperature $\gamma$-ray irradiation by the reaction of interstitial $\mathrm{O}_{2}$ molecules with $\mathrm{H}$ atoms, arising from the radiation induced breaking of $\mathrm{H}_{2} \mathrm{O}$ molecules surrounding the nanoparticles or in the interstices. This generation process is significantly different with respect to that which takes place in bulk silica, where the $\mathrm{H}$ atoms reacting with $\mathrm{O}_{2}$ to generate $\mathrm{HO}_{2}^{\circ}$ radicals arise from radiation induced breaking of $\mathrm{OH}$ bonds in $\mathrm{SiOH}$ or $\mathrm{SiOOH}$ groups. This strong difference in the generation process of $\mathrm{HO}_{2}^{-}$radicals in the two systems is strictly related to the specific surface of the material. In fact, a higher specific surface implies overall a larger number of $\mathrm{H}$ atoms available for unit mass of the material, and produced by radiation induced $\mathrm{H}_{2} \mathrm{O}$ breaking as well as a reduced distance of the trapped $\mathrm{O}_{2}$ molecules from the surface. Both these properties increase significantly the probability of formation of $\mathrm{HO}_{2}^{-}$radicals, making this process of generation actually dominant in materials with high specific surface, as silica nanoparticles.

We also obtained an estimation of $\mathrm{O}_{2}$ concentration from its correlation with generated $\mathrm{HO}_{2}^{-}$radicals and determined a conversion factor in agreement with previous experimental findings that allows to estimate the $\mathrm{O}_{2}$ content in silica nanoparticles from Raman/PL spectra.

\section{Table 5}

$\mathrm{HO}_{2}^{*}$ concentrations and variation of the $\mathrm{O}_{2}$ concentration in AEOX50 samples irradiater in air, in $\mathrm{H}_{2} \mathrm{O}$ and $\mathrm{D}_{2} \mathrm{O}$.

\begin{tabular}{lll}
\hline Name & $-\Delta \mathrm{O}_{2}$ Conc. $\left(\right.$ molec. $\left./ \mathrm{cm}^{3}\right)$ & $\mathrm{HO}_{2}^{\circ}$ Conc. $\left(\mathrm{molec} . / \mathrm{cm}^{3}\right)$ \\
\hline AEOX50 in air & $(1.9 \pm 0.8) \cdot 10^{18}$ & $(1.8 \pm 0.4) \cdot 10^{18}$ \\
AEOX50 in $\mathrm{H}_{2} \mathrm{O}$ & $(3.1 \pm 1.2) \cdot 10^{18}$ & $(2.9 \pm 0.6) \cdot 10^{18}$ \\
AEOX50 in $\mathrm{D}_{2} \mathrm{O}$ & $(2.4 \pm 1.0) \cdot 10^{18}$ & $(2.8 \pm 0.6) \cdot 10^{18}$ \\
\hline
\end{tabular}

\section{Acknowledgement}

We are particularly grateful to K.Kajihara for the preparation of the sample of bulk silica loaded with oxygen. Useful discussions with the members of the LAMP group http://www.fisica.unipa.it/amorphous are gratefully cknowledged. Partial financial support by the FAE-PO FESR SICILIA 2007/2013 4.1.1.1 and by the FFR 2012/2013 project of the University of Palermo is acknowledged.

\section{References}

[1] A.C. Balazs, T. Emrick, T.P. Russell, Nanoparticle polymer composites: Where two small worlds meet, Science 314 (2006) 1107-1110, http://dx.doi.org/10.1126/science. 1130557.

[2] S.E. Pratsinis, Flame aerosol synthesis of ceramic powders, Prog. Energy Combust. Sci. 24 (1998) 197-219, http://dx.doi.org/10.1016/S0360-1285(97)00028-2.

[3] W.J. Stark, S.E. Pratsinis, Aerosol flame reactors for manufacture of nanoparticles, Powder Technol. 126 (2002) 103-108, http://dx.doi.org/10.1016/S0032-5910(02)00077-3.

[4] D.R. Kearns, Physical and chemical properties of singlet molecular oxygen, Chem. Rev. 71 (1971) 395-427, http://dx.doi.org/10.1021/cr60272a004.

[5] A.A. Krasnovsky, Singlet molecular oxygen in photobiochemical systems: IR phosphorescence studies, Membr. Cell Biol. 12 (1998) 665-690.

[6] P. Couleaud, V. Morosini, C. Frochot, S. Richeter, L. Raehm, J.-O. Durand, Silica-based nanoparticles for photodynamic therapy applications, Nanoscale 2 (2010) 1083-1095, http://dx.doi.org/10.1039/CONR00096E.

[7] K. Kajihara, M. Hirano, L. Skuja, H. Hosono, Role of interstitial voids in oxides on formation and stabilization of reactive radicals: interstitial $\mathrm{HO}_{2}$ radicals in $\mathrm{F}_{2}$-laser-irradiated amorphous $\mathrm{SiO}_{2}$, J. Am. Chem. Soc. 128 (2006) 5371-5374, http://dx.doi.org/ 10.1021/ja0571390.

[8] K. Kajihara, T. Miura, H. Kamioka, A. Aiba, M. Uramoto, Y. Morimoto, M. Hirano, L Skuja, H. Hosono, Diffusion and reactions of interstitial oxygen species in amorphous $\mathrm{SiO}_{2}$ : A review, J. Non-Cryst. Solids 354 (2008) 224-232, http://dx.doi.org/ 10.1016/j.jnoncrysol.2007.07.038.

[9] G. Buscarino, S. Agnello, A. Parlato, F.M. Gelardi, Investigation on the generation process of $\mathrm{HO}_{2}^{-}$radicals by $\gamma$-ray irradiation in $\mathrm{O}_{2}$-loaded fumed silica, J. Non-Cryst. Solids 362 (2013) 152-155, http://dx.doi.org/10.1016/j.jnoncrysol.2012.11.040.

[10] Y. Inaki, H. Yoshida, T. Yoshida, T. Hattori, Active sites on mesoporous and amorphous silica materials and their photocatalytic activity: An investigation by FTIR, ESR, VUV-UV and photoluminescence spectroscopies, J. Phys. Chem. B 106 (2002) 49098-49106, http://dx.doi.org/10.1021/jp025768f.

[11] R. Doremus, Diffusion of Reactive Molecules in Solids and Melts, John Wiley, New York, 2002.

[12] S.R. Langhoff, R.L. Jaffe, Theoretical study of the four lowest doublet electronic states of the hydroperoxyl radical: Application to photodissociation, J. Chem. Phys. 71 (1979) $1475-1485$.

[13] D. Mihelcic, A. Volz-Thomas, H.W. Patz, M.M.D. Kley, Numerical analysis of ESR spectra from atmospheric samples, J. Atmos. Chem. 11 (1990) 271-297, http://dx.doi. org/10.1007/BF00118353.

[14] F.J. Adrian, E.L. Cochran, V.A. Bowers, ESR spectrum of $\mathrm{HO}_{2}$ in Argon at $4.2 \mathrm{~K}$, J. Chem Phys. 47 (1967) 5441-5442.

[15] N.A. Chumakova, T.S. Yankova, A.K. Vorobiev, EPR study of orientation distribution function of $\mathrm{HO}_{2}^{-}$radicals ordered by light irradiation, Appl. Magn. Reson. 33 (2008) 117-126, http://dx.doi.org/10.1007/s00723-008-0047-2.

[16] L. Skuja, B. Guttler, Detection of interstitial oxygen molecules in $\mathrm{SiO}_{2}$ glass by a direct photoexcitation of the infrared luminescence of singlet $\mathrm{O}_{2}$, Phys. Rev. Lett. 77 (1996) 2093, http://dx.doi.org/10.1103/PhysRevLett.77.2093.

[17] S. Agnello, M. Cannas, L. Vaccaro, G. Vaccaro, F.M. Gelardi, M. Leone, V. Militello, R. Boscaino, Near-infrared emission of $\mathrm{O}-2$ embedded in amorphous $\mathrm{SiO}_{2}$ nanoparticles, J. Phys. Chem. C 115 (2011) 612831-612835, http://dx.doi.org/10.1021/ jp2035554.

[18] K. Kajihara, H. Kamioka, M. Hirano, T. Miura, L. Skuja, H. Hosono, Interstitial oxygen molecules in amorphous $\mathrm{SiO}_{2}$. II. the influence of common dopants $(\mathrm{SiOH}, \mathrm{SiF}$, and $\mathrm{SiCl}$ groups) and fictive temperature on the decay of singlet photoluminescence, J. Appl. Phys. 98 (2005) 013528, http://dx.doi.org/10.1063/1.1943505.

[19] K. Kajihara, H. Kamioka, M. Hirano, T. Miura, L. Skuja, H. Hosono, Interstitial oxygen molecules in amorphous $\mathrm{SiO}_{2}$. iii. measurements of dissolution kinetics, diffusion coefficient, and solubility by infrared photoluminescence, J. Appl. Phys. 98 (2005) 013529 .

[20] C. Schweitzer, R. Schmidti, Physical mechanisms of generation and deactivation of singlet oxygen, Chem. Rev. 103 (2003) 16851758, http://dx.doi.org/10.1021/ cr010371d.

[21] G. Vaccaro, Structural modifcation processes in bulk and nano-sized amorphous SiO2 systems, (Ph.D. thesis) Universita' degli Studi di Palermo, Italy, 2011.

[22] A. Alessi, G. Iovino, G. Buscarino, S. Agnello, F.M. Gelardi, Entrapping of O-2 molecules in nanostructured silica probed by photoluminescence, J. Phys. Chem. C 117 (2013) 2616-2622, http://dx.doi.org/10.1021/jp310314t.

[23] K. Kajihara, T. Miura, H. Kamioka, M. Hirano, L. Skuja, H. Hosono, Diffusion of oxygen molecules in fluorine-doped amorphous $\mathrm{SiO}_{2}$, Mater. Sci. Eng. B 173 (2010) 158-161, http://dx.doi.org/10.1016/j.mseb.2010.01.002.

[24] S. Agnello, D.D. Francesca, A. Alessi, G. Iovino, M. Cannas, S. Girard, A. Boukenter, Y. Ouerdane, Interstitial O-2 distribution in amorphous $\mathrm{SiO}_{2}$ nanoparticles determined by raman an photoluminescence spectroscopy, J. Appl. Phys. 114 (104305) (2013) 1-6. 
[25] R.J. Hemley, H.K. Mao, P.M. Bell, B.O. Mysen, Raman spectroscopy of SiO-2 glass at high pressure, Phys. Rev. Lett. 57 (1986) 747, http://dx.doi.org/10.1103/PhysRevLett.57.747.

[26] S. Agnello, R. Boscaino, M. Cannas, F.M. Gelardi, Instantaneous diffusion effect on spin-echo decay: Experimental investigation by spectral selective excitation, Phys. Rev. B 64 (174423) (2001) 1-5, http://dx.doi.org/10.1103/PhysRevB.64.174423.

[27] Evonik industries online catalog2010.

[28] R. Stolen, G. Walrafen, Water and its relation to broken bond defects in fused silica, J. Chem. Phys. 64 (1976) 2623.

[29] T. Yamada, M. Nakajima, T. Suemoto, T. Uchino, Formation and photoluminescence characterization of transparent silica glass prepared by solid-phase reaction of nanometer-sized silica particles, J. Chem. Phys. C 111 (2007) 12973-12979.

[30] G.-L. Davies, J.E. McCarthy, A. Rakovichb, Y.K. Gunko, Towards white luminophores: developing luminescent silica on the nanoscale, J. Mater. Chem. 22 (2012) 7358

[31] F. Galeener, G. Lucovsky, Longitudinal optical vibrations in glasses: $\mathrm{GeO}_{2}$ and $\mathrm{SiO}_{2}$, Phys. Rev. Lett. 37 (1976) 1474

[32] F.L. Galeener, A.E. Geissberger, Vibrational dynamics in ${ }^{30} \mathrm{Si}$-substituted vitreous $\mathrm{SiO}_{2}$, Phys. Rev. B 27 (1983) 6199, http://dx.doi.org/10.1103/PhysRevB.27.6199.

[33] A. Geissberger, F. Galeener, Raman studies of vitreous SiO-2 versus fictive temperature, Phys. Rev. B 28 (1983) 3266, http://dx.doi.org/10.1103/PhysRevB.28.3266.

[34] G. Iovino, S. Agnello, F.M. Gelardi, R. Boscaino, O-2 diffusion in amorphous $\mathrm{SiO}_{2}$ nanoparticles probed by outgassing, J. Phys. Chem. C 116 (2012) 11351-11356, http://dx.doi.org/10.1021/jp3006734.
[35] J.R. Scherer, M.K. Go, S. Kint, Raman spectra and structure of water from -10 to $90 \mathrm{deg}, \mathrm{J}$. Phys. Chem. 78 (1974) 1304-1313, http://dx.doi.org/10.1021/j100606a013.

[36] L. Skuja, B. Guttler, D. Schiel, A. Silin, Quantitative analysis of the concentration of interstitial 0-2 molecules in $\mathrm{SiO}_{2}$ glass using luminescence and Raman spectrometry, J. Appl. Phys. 83 (1998) 6106-6110, http://dx.doi.org/10.1063/1.367480.

[37] H.-B. Sun, S. Juodkazisi, M. Watanabe, S. Matsuo, H. Misawa, J. Nishii, Generation and recombination of defects in vitreous silica induced by irradiation with a nearinfrared femtosecond laser, J. Phys. Chem. B 104 (2000) 3450-3455, http://dx.doi. org/10.1021/jp992828h.

[38] G. Vaccaro, S. Agnello, G. Buscarino, F. Gelardi, Thermally induced structural modification of silica nanoparticles investigated by Raman and infrared absorption spectroscopies, J. Chem. Phys. C 114 (2010) 13991-13997, http://dx.doi.org/10.1021/ jp103565a.

[39] V.V. Hoanga, D. Gangulib, Amorphous nanoparticles experiments and computer simulations, Phys. Rep. 518 (2012) 81-140, http://dx.doi.org/10.1016/j.physrep. 2012.07.004.

[40] C. Barb, J. Bartlett, L. Kong, K. Finnie, H. Lin, M. Larkin, S. Calleja, A. Bush, G. Calleja, Silica particles: A novel drug-delivery system, Adv. Mater. 16 (2004) 1959, http:// dx.doi.org/10.1002/adma.200400771.

[41] L. Nuccio, S. Agnello, R. Boscaino, Role of $\mathrm{H}-2 \mathrm{O}$ in the thermal annealing of the $\mathrm{E}_{\gamma}$ center in amorphous silicon dioxide, Phys. Rev. B 79 (2009) 1-8, http://dx.doi.org/ 10.1103/PhysRevB.79.125205. 